\title{
Efficacy of Milrinone Plus Sildenafil in the Treatment of Neonates with Persistent Pulmonary Hypertension in Resource-Limited Settings: Results of a Randomized, Double-Blind Trial
}

\author{
Mamdouh El-Ghandour $^{1} \cdot$ Bahaa Hammad ${ }^{1} \cdot$ Mohamed Ghanem $^{1} \cdot$ Manal A. M. Antonios ${ }^{1}$
}

Published online: 28 August 2020

(c) Springer Nature Switzerland AG 2020

\begin{abstract}
Background The management of severe persistent pulmonary hypertension (PPHN) can be very challenging in many resource-limited centers without access to inhaled nitric oxide or extracorporeal membrane oxygenation.

Objectives The current study aimed to investigate the efficacy of oral sildenafil and intravenous milrinone infusion and compare the effects of these drugs in combination versus as monotherapy in neonates with PPHN.

Methods A double-blind randomized controlled trial was conducted in which neonates with PPHN were divided into three groups of 20 patients each: group 1 received oral sildenafil starting at $0.5 \mathrm{mg} / \mathrm{kg}$ every $6 \mathrm{~h}$ to a target maintenance dose of $2 \mathrm{mg} / \mathrm{kg}$ every $6 \mathrm{~h}$; group 2 received intravenous milrinone $0.5 \mu \mathrm{g} / \mathrm{kg} / \mathrm{min}$ as a continuous infusion; and group 3 received both oral sildenafil and intravenous milrinone.

Results Post-treatment pulmonary artery systolic pressure was significantly lower in group 3 than in groups 1 and 2 , which both received monotherapy $(p=0.031)$. The oxygenation index also decreased significantly in the dual-therapy group $(p=0.002)$ compared with the monotherapy groups. Combined use of both drugs demonstrated a beneficial synergistic effect with better outcomes and reduced mortality.

Conclusion Dual therapy using sildenafil and milrinone was superior to monotherapy with either drug in neonates with severe PPHN and is recommended for use in resource-constrained settings.

Registration Pan African Clinical Trial Registry identifier number PACTR201902691230243.
\end{abstract}

\section{Introduction}

A series of circulatory events takes place at birth to ensure a smooth transition from fetal to extrauterine life. Clamping of the umbilical cord removes low-resistance placental circulation and increases systemic arterial pressure. Simultaneously, various mechanisms operate to rapidly reduce pulmonary arterial pressure and increase pulmonary blood flow.

Manal A. M. Antonios

malakmanal@yahoo.com

Mamdouh El-Ghandour

mamdouhelghandour62@gmail.com

Bahaa Hammad

bahahammad@yahoo.com

Mohamed Ghanem

docmgamal@gmail.com

1 Department of Pediatrics, Faculty of Medicine, El-Shatby

Hospital, Alexandria University, Alexandria, Egypt

\section{Key Points}

Neonates with persistent pulmonary hypertension (PPHN) should ideally receive inhaled nitric oxide and extracorporeal membrane oxygenation.

In newborn care units lacking this gold standard therapy for PPHN, treatment comprises pulmonary vasodilators such as oral sildenafil or continuous intravenous infusion of milrinone.

In the current randomized controlled trial, sildenafil combined with milrinone was more effective at normalizing pulmonary artery pressure and improving survival rates than treatment with either of the two drugs as monotherapy. 
Of these, the most important stimuli appear to be ventilation of the lungs and increased oxygen tension [1].

Failure of the pulmonary circulation to undergo the normal transition after birth leads to persistent pulmonary hypertension (PPHN), which is characterized by an elevated pulmonary/systemic vascular resistance ratio resulting from either vasoconstriction, structural remodeling of the pulmonary vasculature, intravascular obstruction, or lung hypoplasia. Right-to-left shunting of blood across the foramen ovale and ductus arteriosus results in hypoxemia and labile oxygen saturations [1].

The use of inhaled nitric oxide (iNO) therapy to obtain a sustained oxygenation response has a high failure rate, which has led to a search for other targets to enhance pulmonary vasodilatation. Two of the most promising therapies are oral sildenafil to stop cyclic guanosine monophosphate (cGMP) from degrading phosphodiesterase 5 and the use of intravenous milrinone to stop cyclic adenosine monophosphate (cAMP) from degrading phosphodiesterase 3 [2].

In developing countries, the high cost of iNO renders it unavailable; advanced ventilator support such as extracorporeal membrane oxygenation (ECMO) is also unavailable. This has necessitated a search for less expensive but effective therapies to allow the stabilization of neonates with PPHN [3].

Because many patients do not respond to monotherapy with milrinone or sildenafil, the current study aimed to investigate the efficacy of combined therapy.

\section{Subject and Methods}

\subsection{Study Setting and Design}

A double-blind randomized controlled trial (RCT) was conducted in the neonatal intensive care unit of Alexandria University Children's Hospital, a tertiary care hospital. The study was registered in the Pan African Clinical Trial Registry database [4] (identification number: PACTR201902691230243) and was approved by the institutional review board of the Faculty of Medicine, Alexandria University. Written informed consent was obtained from the legal guardian of all patients enrolled in the study.

\subsection{Population}

\subsubsection{Inclusion Criteria}

All newborn cases aged between 1 and 28 days, diagnosed with PPHN by echocardiography, and indicated for treatment were recruited for the study. A pediatric echocardiographer with 30 years of experience was blinded to the clinical trial groups and performed echocardiography using a GE vivid
S5 ultrasound machine with a $7 \mathrm{MHz}$ probe. M-mode, 2D, and color Doppler mode, with pulsed and continuous waves, were used to evaluate pulmonary artery pressure using the modified Bernoulli equation: pulmonary artery systolic pressure $(\mathrm{PASP})=$ tricuspid regurgitation gradient + right atrial pressure (RAP), PASP $=\left(V_{\max }^{2} \times 4\right)+\mathrm{RAP}$. Neonates with PPHN were those with PASP $>40 \mathrm{mmHg}$ [5]. Tricuspid regurgitation was graded as mild, moderate, or severe, according to Go et al. [6].

\subsubsection{Exclusion Criteria}

We excluded neonates with any congenital heart disease, congenital diaphragmatic hernia, or lung anomalies and candidates for major surgical interventions.

The study population was randomized into the following three groups in a double-blind manner: group 1 received oral sildenafil starting at $0.5 \mathrm{mg} / \mathrm{kg}$ every $6 \mathrm{~h}$ with increments of $0.5 \mathrm{mg} / \mathrm{kg} / \mathrm{dose}$ and a target maintenance dose of $2 \mathrm{mg} / \mathrm{kg}$ every $6 \mathrm{~h}$; group 2 received intravenous milrinone $0.5 \mu \mathrm{g} /$ $\mathrm{kg} / \mathrm{min}$ as a continuous infusion; group 3 received both oral sildenafil and intravenous milrinone. Block randomization was conducted using web-based software [7] to assign a patient to one of the three groups in a 1:1:1 ratio and using sequentially numbered sealed envelopes. Drug therapy was administered for 14 days.

\subsection{Endpoints}

The primary endpoint was improvement of PASP after $24 \mathrm{~h}$ of treatment. Doppler echocardiography examination was done on day 1 (first $24 \mathrm{~h}$ ) for all neonates included in this study. Follow-up Doppler echocardiography was performed after receiving medical therapy on the following schedule:

- within $24 \mathrm{~h}$ from the start of treatment

- as soon as possible for any case showing progressive respiratory distress and/or increased oxygen requirements

- follow-up was continued for 3 months according to the clinical condition of the case until clinical and echocardiographic improvement or death.

The secondary outcome was clinical improvement and fate during and until the end of the study duration.

\subsection{Statistical Consideration}

A sample size of 20 patients per group (total sample size 60) was estimated as sufficient to provide statistical significance with $80 \%$ power and at a significance level of $95 \%$ (accepted $\alpha$ error $=0.05$ ) [8]. We used SPSS (Statistical Package for the Social Sciences) version 21 for statistical analysis. Since the Kolmogorov-Smirnov test of normality 


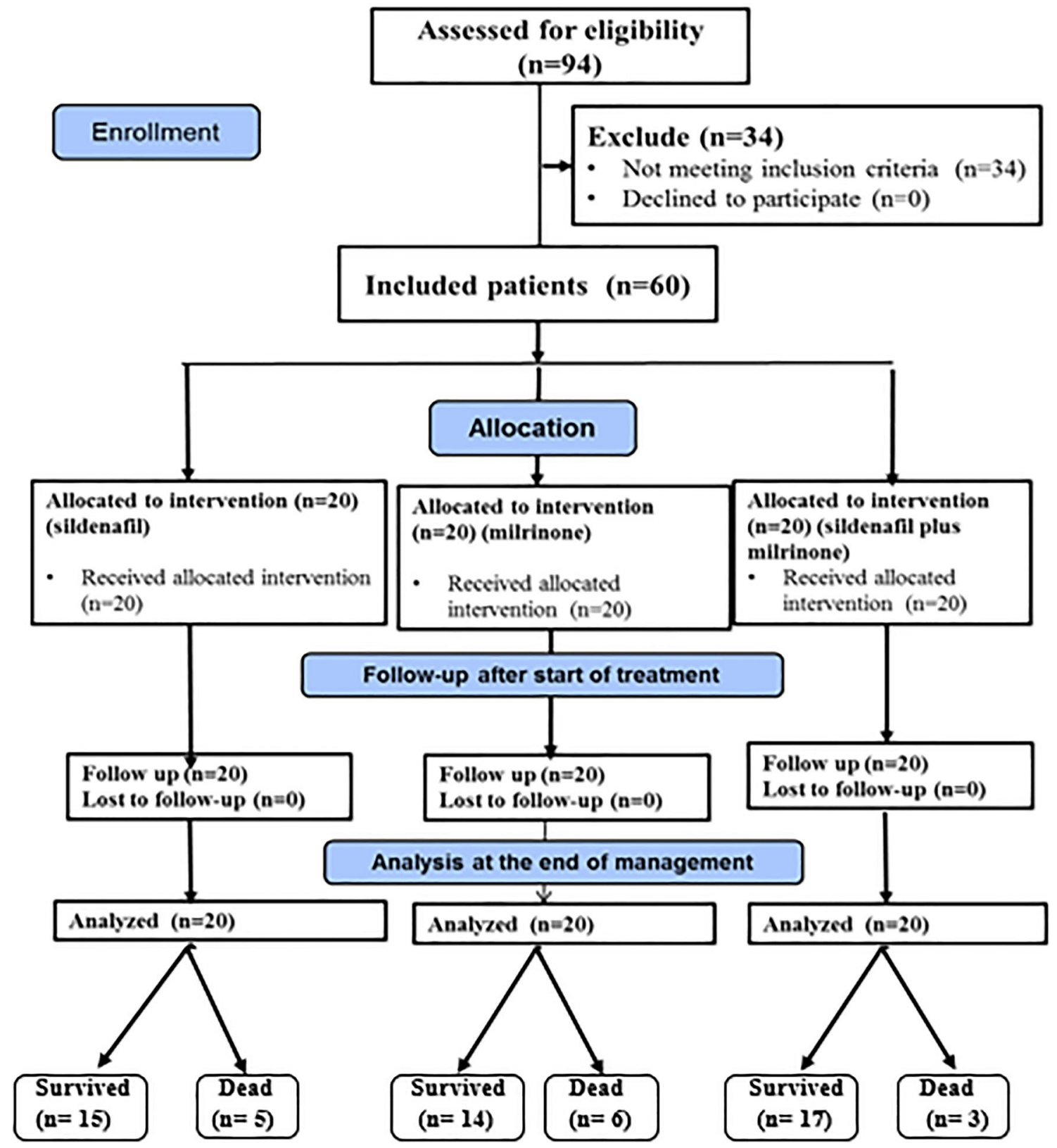

Fig. 1 CONSORT (Consolidated Standards of Reporting Trials) flow diagram of the study design

revealed significance in the distribution of some variables, we adopted nonparametric statistics. Comparisons were conducted between independent subgroups with nonnormal distribution using the Mann-Whitney $U$ test. The Kruskal-Wallis test was used if more than two independent subgroups were studied. When the Kruskal-Wallis test was significant, post hoc pairwise comparisons were carried out using the Dunn-Sidak test for multiple comparisons. Pearson's correlation and point-biserial correlation were performed. The Chi squared test was used to test the association between qualitative variables. Monte Carlo corrections were carried out when indicated.

\section{Results}

Figure 1 shows the process used for the recruitment of the study population and the outcomes of the three groups studied in this clinical trial.

No statistically significant differences were found among the three groups in terms of weight, stage of maturity, 
and sex. Group 3 (dual therapy) took longer to normalize PASP $(p=0.036)$ and had the lowest incidence of mortality $(n=3[15 \%])$, although this was not statistically significant (Table 1).

The number of patients with patent ductus arteriosus (PDA) decreased through the course of management, but the size of ductus that remained patent at the end of management was not affected by the treatment received in the three groups (Table 2).

Although group 3 had significantly more severe cases of tricuspid regurgitation $(p=0.03)$, there was no statistical difference between the three groups at day 2 and at the end of management ( $p=0.974$ and $p=0.771$, respectively) (Table 3).

Assessment of left ventricular functions and mitral valve revealed that all cases in all three groups $(n=60)$ were completely normal at the beginning of the study, at day 2 , and at the end of management.

Interestingly, PASP was significantly higher in group 3 at day 1 before the start of therapy $(p=0.002)$ but significantly lower than that in the two groups receiving monotherapy $(p=0.031)$ (Table 4).

The pairwise comparison of the effect of sildenafil was not statistically significant early in the course of therapy (from day 1 to day $2 ; p=0.105$ ), but at the end of management there was a statistically significant decrease in PASP (from day 1 to the end of management; $p=0.001$ ) (Fig. 2a).

The pairwise comparison of the effect of milrinone showed a statistical decrease of the PASP early in the course of therapy (from day 1 to day $2 ; p=0.03$ ), but milrinone was not significantly effective in the later part of the trial (from day 2 to the end of management; $p=0.215$ ) (Fig. 2b).

The pairwise comparison in the dual therapy group showed statistically significant improvement of PASP in both the early and the later phase of therapy (from day 1 to day 2 [ $p=0.011]$, from day 2 to end of management [ $p=0.045]$, and from day 1 to end of management $[p<0.001]$ ) (Fig. 2c).

The oxygenation index statistically decreased among the sildenafil group and the dual therapy group $(p=0.041$ and $p=0.002$, respectively), but the decrease was not statistically proven among the milrinone group (Table 5).

Systolic and diastolic blood pressure before and after treatment did not differ in any of the groups (Table 6).

\section{Discussion}

The current study aimed to evaluate the effect of oral sildenafil plus intravenous milrinone infusion in newborns with PPHN compared with the use of monotherapy with either of these agents.

Results from the current study showed that the combination of oral sildenafil and intravenous milrinone resulted in improved clinical outcomes, reflected by reduced mortality and a significant decrease in PASP. In group 1 (sildenafil only), there was no significant change in PASP from day 1 to day 2 , with the difference only appearing at the end of management. This may be because sildenafil needs a longer treatment duration to induce a therapeutic effect. For group 2 (milrinone only), there was a significant decrease in PASP from day 1 to day 2 but no significant change in PASP from day 2 to the end of management. This may reflect that milrinone induced its therapeutic effect rapidly, but some sort of tolerance arose with continuing management as no further beneficial effect was seen. Group 3 (combined therapy) had a significant decrease in PASP from day 1 to day 2 and from day 2 to the end of management, suggesting that the dual therapy had a rapid therapeutic effect, and PASP continued to improve until normalization with no apparent tolerance arising. The use of milrinone in combination with sildenafil in a resource-limited setting has demonstrated a beneficial synergistic effect with better outcomes, especially in severe PPHN.

To the best of our knowledge, only a few studies have assessed the combined effect of sildenafil and milrinone in humans for the treatment of PPHN. An experimental study evaluated sildenafil and milrinone in combination after inducing pulmonary hypertension in 24 adult swines. This study demonstrated a statistically significant decline in pulmonary vascular resistance and improved cardiac output in the group that received the combination therapy. We conclude that milrinone and sildenafil are effective pulmonary vasodilators with independent actions and an additive effect [9].

In a retrospective study, Khorana et al. [10] examined 40 infants with PPHN. All infants received standard therapy with mechanical ventilation, sedation, and inotropic drugs: 11 received oral sildenafil, and 6 of these responded to the drug. Three of the five nonresponders showed an improvement in their oxygenation when their treatment was combined with another pulmonary vasodilator such as milrinone.

A Cochrane meta-analysis from 2007 included two eligible trials from resource-limited settings and showed significant improvement in oxygenation in those receiving sildenafil compared with those receiving placebo [11]. Prithviraj et al. [12] conducted a prospective observational study to evaluate the use of oral sildenafil in neonates with PPHN and demonstrated improvement in oxygenation index and a decrease in PASP.

Milrinone has also shown effectiveness in reducing pulmonary vascular resistance and PASP in experimental models of pulmonary hypertension in adult humans and neonates [13-15].

Managing severe PPHN without the use of iNO or ECMO is challenging. In such situations, dual therapy using oral 
Table 1 Comparison of clinical data among the three studied groups

\begin{tabular}{|c|c|c|c|c|}
\hline Data & $\begin{array}{l}\text { Group } 1 \\
\text { Sildenafil alone }(n=20)\end{array}$ & $\begin{array}{l}\text { Group } 2 \\
\text { Milrinone alone }(n=20)\end{array}$ & $\begin{array}{l}\text { Group } 3 \\
\text { Sildenafil plus mil- } \\
\text { rinone }(n=20)\end{array}$ & Test of significance \\
\hline \multicolumn{4}{|l|}{ Weight (kg) } & \multirow{4}{*}{$\begin{array}{l}\chi_{(\mathrm{KW})}^{2}=0.101 \\
p=0.951\end{array}$} \\
\hline Min; max & $2.20 ; 3.70$ & $1.80 ; 4.00$ & $2.10 ; 3.70$ & \\
\hline Mean \pm SD & $3.00 \pm 0.44$ & $3.02 \pm 0.55$ & $2.96 \pm 0.46$ & \\
\hline Median (IQR) & $3.00(2.65-3.35)$ & $3.00(2.70-3.4)$ & $3.00(2.65-3.4)$ & \\
\hline \multicolumn{4}{|l|}{ Stage of maturity } & \multirow{4}{*}{$\begin{array}{l}\chi^{2}=1.336 \\
p_{(\mathrm{MC})}=0.884\end{array}$} \\
\hline Full term & $14(70)$ & $12(60)$ & $12(60)$ & \\
\hline Late preterm & $5(25)$ & $6(30)$ & $5(25)$ & \\
\hline Post date & $1(5)$ & $2(10)$ & $3(15)$ & \\
\hline \multicolumn{4}{|l|}{ Sex } & \multirow{3}{*}{$\begin{array}{l}\chi^{2}=1.905 \\
p_{(\mathrm{MC})}=0.386\end{array}$} \\
\hline Male & $16(80)$ & $14(70)$ & $12(60)$ & \\
\hline Female & $4(20)$ & $6(30)$ & $8(40)$ & \\
\hline Cases with heart failure & $2(10)$ & $1(5)$ & $5(25)$ & $\begin{array}{l}\chi^{2}=3.750 \\
p_{(\mathrm{MC})}=0.241\end{array}$ \\
\hline \multicolumn{4}{|l|}{ Length to normalize PASP (days) } & \multirow{4}{*}{$\begin{array}{l}\chi^{2}=6.671 \\
p=0.036^{*}\end{array}$} \\
\hline Min; $\max$ & $5.00 ; 18.00$ & $6.00 ; 17.00$ & $9.00 ; 26.00$ & \\
\hline Mean \pm SD & $10.80 \pm 3.23$ & $10.43 \pm 2.65$ & $13.82 \pm 4.95$ & \\
\hline Median (IQR) & $11.00(9.0-13.0)$ & $10.00(9.0-11.0)$ & $12.00(11.0-14.0)$ & \\
\hline \multicolumn{4}{|l|}{ Outcome } & \multirow{3}{*}{$\begin{array}{l}\chi^{2}=1.304 \\
p_{(\mathrm{MC})}=0.644\end{array}$} \\
\hline Improved & $15(75)$ & $14(70)$ & $17(85)$ & \\
\hline Deceased & $5(25)$ & $6(30)$ & $3(15)$ & \\
\hline
\end{tabular}

Data are presented as $N(\%)$ unless otherwise indicated

$I Q R$ interquartile range, $K W$ Kruskal-Wallis test, $M C$ Monte Carlo test, max maximum, min minimum, PASP pulmonary artery systolic pressure, $S D$ standard deviation

*Significant $p$ value $<0.05$

Table 2 Comparison of patent ductus arteriosus size within the three groups at different stages of the study

\begin{tabular}{|c|c|c|c|c|}
\hline PDA size $(\mathrm{mm})$ & $\begin{array}{l}\text { Group } 1 \\
\text { Sildenafil alone }\end{array}$ & $\begin{array}{l}\text { Group } 2 \\
\text { Milrinone alone }\end{array}$ & $\begin{array}{l}\text { Group } 3 \\
\text { Sildenafil plus milrinone }\end{array}$ & Test of significance \\
\hline \multicolumn{4}{|l|}{ Day 1} & \multirow{5}{*}{$\begin{array}{l}\chi^{2}=0.040 \\
p=0.980\end{array}$} \\
\hline$n$ & 11 & 14 & 16 & \\
\hline Min; $\max$ & $2.80 ; 4.50$ & $2.20 ; 6.00$ & $2.60 ; 7.20$ & \\
\hline Mean \pm SD & $3.75 \pm 0.55$ & $3.79 \pm 0.99$ & $4.11 \pm 1.43$ & \\
\hline Median (IQR) & $3.80(3.30-4.40)$ & $3.80(3.20-4.00)$ & $3.70(3.10-5.00)$ & \\
\hline \multicolumn{4}{|l|}{ Day 2} & \multirow{5}{*}{$\begin{array}{l}\chi^{2}=0.003 \\
p=0.998\end{array}$} \\
\hline$n$ & 11 & 14 & 15 & \\
\hline Min; $\max$ & $2.50 ; 4.50$ & $1.60 ; 4.50$ & $2.10 ; 7.10$ & \\
\hline Mean \pm SD & $3.48 \pm 0.62$ & $3.40 \pm 0.73$ & $3.89 \pm 1.55$ & \\
\hline Median (IQR) & $3.40(3.00-4.00)$ & $3.50(3.00-3.80)$ & $3.00(3.00-5.00)$ & \\
\hline \multicolumn{4}{|l|}{ At end of management } & \multirow{5}{*}{$\begin{array}{l}\chi^{2}=2.694 \\
p=0.260\end{array}$} \\
\hline$n$ & 2 & 3 & 3 & \\
\hline Min; $\max$ & $3.80 ; 4.00$ & $2.00 ; 3.50$ & $2.50 ; 6.50$ & \\
\hline Mean \pm SD & $3.90 \pm 0.14$ & $2.90 \pm 0.79$ & $4.67 \pm 2.02$ & \\
\hline Median (IQR) & $3.90(3.80-4.00)$ & $3.20(2.00-3.50)$ & $5.00(2.50-6.50)$ & \\
\hline
\end{tabular}

$I Q R$ interquartile range, $\max$ maximum, $\min$ minimum, $P D A$ patent ductus arteriosus, $S D$ standard deviation 
Table 3 Comparison of right ventricular function and categories of tricuspid regurgitation within the three groups at different stages of the study

\begin{tabular}{|c|c|c|c|c|}
\hline RVF and TR & $\begin{array}{l}\text { Group } 1 \\
\text { Sildenafil alone }\end{array}$ & $\begin{array}{l}\text { Group } 2 \\
\text { Milrinone alone }\end{array}$ & $\begin{array}{l}\text { Group } 3 \\
\text { Sildenafil plus milrinone }\end{array}$ & Test of significance \\
\hline Day 1 & & & & $\chi^{2}=13.438$ \\
\hline Normal & $2(100)$ & $0(0.0)$ & $0(0.0)$ & $p_{(\mathrm{MC})}=0.030^{*}$ \\
\hline Mild TR & $9(33.33)$ & $13(48.15)$ & $5(18.52)$ & \\
\hline Moderate TR & $7(41.18)$ & $3(17.65)$ & $7(41.18)$ & \\
\hline Severe TR & $2(14.29)$ & $4(28.57)$ & $8(57.14)$ & \\
\hline Day 2 & & & & $\chi^{2}=1.669$ \\
\hline Normal & $5(33.33)$ & $4(26.67)$ & $6(40.00)$ & $p_{(\mathrm{MC})}=0.974$ \\
\hline Mild TR & $10(34.48)$ & $10(34.48)$ & $9(31.03)$ & \\
\hline Moderate TR & $3(30.00)$ & $3(30.00)$ & $4(40.00)$ & \\
\hline Severe TR & $2(33.33)$ & $3(50.00)$ & $1(16.67)$ & \\
\hline At end of management & & & & $\chi^{2}=1.804$ \\
\hline Normal & $10(31.25)$ & $8(25.0)$ & $14(43.75)$ & $p_{(\mathrm{MC})}=0.771$ \\
\hline Mild TR & $0(0.0)$ & $0(0.0)$ & $0(0.0)$ & \\
\hline Moderate TR & $1(50.00)$ & $1(50.00)$ & $0(0.0)$ & \\
\hline Severe TR & $4(33.33)$ & $5(41.67)$ & $3(25.00)$ & \\
\hline
\end{tabular}

Data are presented as $n(\%)$ within the TR group

$M C$ Monte Carlo test, $R V F$ right ventricular function, $T R$ tricuspid regurgitation

*Significant $p$ value $<0.05$

Table 4 Comparison of the three groups regarding pulmonary arterial systolic pressure at different treatment stages

\begin{tabular}{|c|c|c|c|c|}
\hline PASP & $\begin{array}{l}\text { Group } 1 \\
\text { Sildenafil alone }(n=20)\end{array}$ & $\begin{array}{l}\text { Group } 2 \\
\text { Milrinone alone }(n=20)\end{array}$ & $\begin{array}{l}\text { Group } 3 \\
\text { Sildenafil plus mil- } \\
\text { rinone }(n=20)\end{array}$ & Test of significance \\
\hline \multicolumn{4}{|l|}{ Day 1} & \multirow{4}{*}{$\begin{array}{l}\chi_{(\mathrm{KW})}^{2}=12.618 \\
p=0.002^{*}\end{array}$} \\
\hline Min; $\max$ & $46.00 ; 91.00$ & $45.00 ; 82.00$ & $50.00 ; 100.00$ & \\
\hline Mean \pm SD & $57.45 \pm 10.36$ & $66.05 \pm 11.73$ & $72.10 \pm 14.94$ & \\
\hline Median (IQR) & $55.00(50.0-60.0)$ & $67.50(55.50-76.50)$ & $69.00(61.00-85.00)$ & \\
\hline \multicolumn{4}{|l|}{ Day 2} & \multirow{4}{*}{$\begin{array}{l}\chi_{(\mathrm{KW})}^{2}=4.857 \\
p=0.088\end{array}$} \\
\hline Min; max & $41.00 ; 75.00$ & $40.00 ; 80.00$ & $40.00 ; 100.00$ & \\
\hline Mean \pm SD & $53.55 \pm 9.48$ & $61.05 \pm 11.60$ & $56.70 \pm 15.97$ & \\
\hline Median (IQR) & $50.00(45.00-60.00)$ & $61.00(52.50-70.00)$ & $54.50(45.00-60.00)$ & \\
\hline \multicolumn{4}{|l|}{ At end of management } & \multirow{5}{*}{$\begin{array}{l}\chi_{(\mathrm{KW})}^{2}=6.923 \\
p=0.031 *\end{array}$} \\
\hline Min; $\max$ & $28.00 ; 81.00$ & $28.00 ; 85.00$ & $22.00 ; 100.00$ & \\
\hline Mean \pm SD & $41.05 \pm 16.75$ & $45.90 \pm 21.51$ & $38.60 \pm 23.59$ & \\
\hline Median (IQR) & $34.5(30.0-49.0)$ & $35.00(30.5-70.00)$ & $30.00(27.5-33.50)$ & \\
\hline Test of significance (within group) & $\begin{array}{l}\chi^{2}=12.182 \\
p=0.002 *\end{array}$ & $\begin{array}{l}\chi^{2}=16.333 \\
p=0.000^{*}\end{array}$ & $\begin{array}{l}\chi^{2}=30.152 \\
p=0.000^{*}\end{array}$ & \\
\hline
\end{tabular}

PASP is presented in $\mathrm{mmHg}$

$I Q R$ interquartile range, $K W$ Kruskal-Wallis test, max maximum, min minimum, $P A S P$ pulmonary artery systolic pressure, $S D$ standard deviation

${ }^{*} p<0.05$

sildenafil and intravenous milrinone infusion might be a suitable option.

Importantly, no significant side effects were found with this combination of drugs; in particular, no decrease in systolic or diastolic blood pressure was observed in any recipients. This has also been observed in other studies $[12,16,17]$. Therefore, all available data indicate that dual 
Fig. 2 Pairwise comparison of therapeutic effect at three different points: day 1 , day 2 , and at the end of management

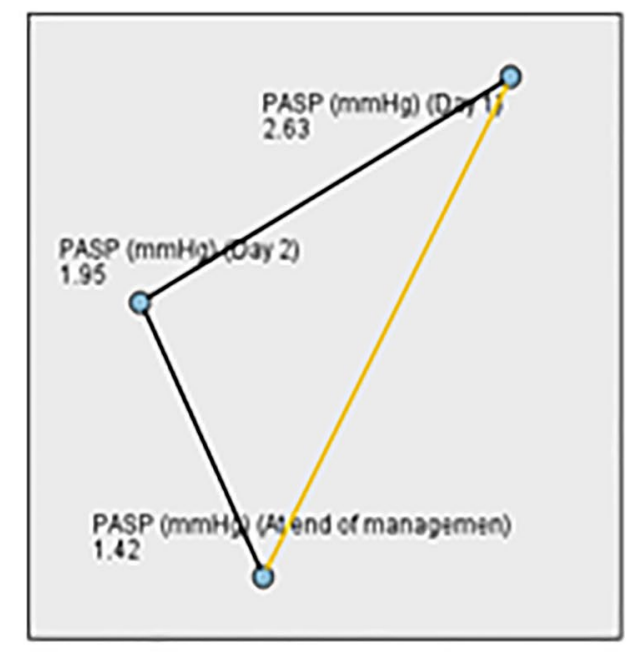

Fig [2/a] Sildenafil group Significant decrease of PASP late (from day 1 to the endpoint, $p=0.001$ )

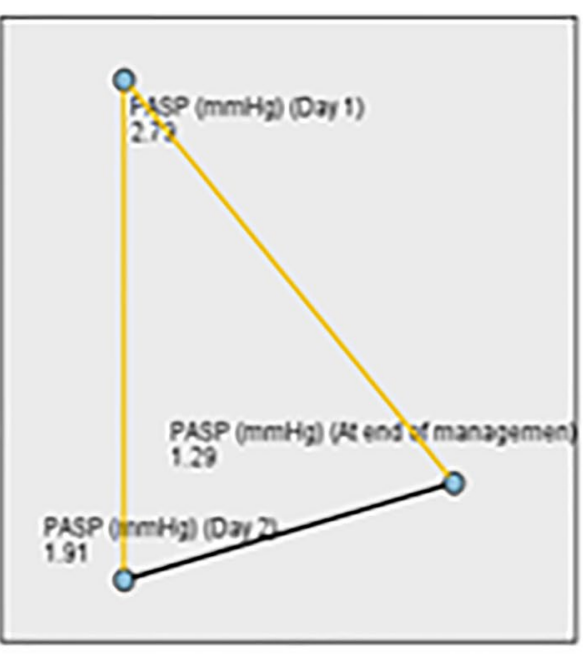

Fig [2/b] Milrinone group Significant decrease of PASP early (from day 1 to day 2, $p=0.03$ )

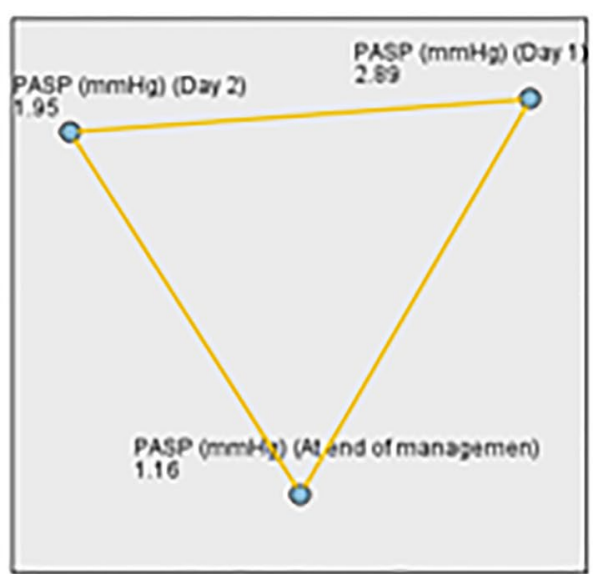

Fig [2/c] Group of dual therapy
Significant decrease of PASP early (from day 1 to $2, p=0.011$ ) and significant decrease late (from day 2 to the endpoint, $p=0.045$ )
Each node shows the sample average rank.

- Significant painise inter-nodal comparison $(p<0.05)$ Non-significant pairwise inter-nodal comparison therapy does not decrease systemic blood pressure as a side effect in patients with severe PPHN.

This study was not without limitations. First, the study was conducted in one center, and results were dependent on the type of supportive care provided in this center so results are not generalizable. A second limitation is the relatively small sample size even though we calculated it to give $80 \%$ power for the statistical analysis. For more robust results, the study should be repeated in a larger population and in multiple settings. Third, the clinical trial was designed to compare the effects of the drugs without the gold standard therapy for severe PPHN (iNO and ECMO) being used as a comparator. However, these results remain crucial for developing countries without access to the gold standard therapy. Lastly, the relatively short duration of follow-up for patients in this study did not allow a comparison of the neurodevelopmental outcomes of the three treatment groups.

\section{Conclusion}

Combined therapy with oral sildenafil and intravenous milrinone had significantly better outcomes than monotherapy with either agent in neonates with PPHN. The combination delivered added therapeutic effect with no additional side effects over the study duration of 3 months. Future trials with longer durations and more patients are needed to 
Table 5 Comparison of oxygenation index before and after treatment among the three groups

\begin{tabular}{|c|c|c|c|c|}
\hline Oxygenation index (\%) & $\begin{array}{l}\text { Group } 1 \\
\text { Sildenafil alone }(n=20)\end{array}$ & $\begin{array}{l}\text { Group } 2 \\
\text { Milrinone alone }(n=20)\end{array}$ & $\begin{array}{l}\text { Group } 3 \\
\text { Sildenafil plus milrinone } \\
(n=20)\end{array}$ & Test of significance \\
\hline \multicolumn{4}{|l|}{ Before treatment } & \multirow{4}{*}{$\begin{array}{l}\chi_{(\mathrm{KW})}^{2}=1.701 \\
p=0.427\end{array}$} \\
\hline Min; $\max$ & $25.00 ; 50.00$ & $20.0 ; 50.0$ & $25.0 ; 45.0$ & \\
\hline Mean \pm SD & $33.0 \pm 6.37$ & $34.0 \pm 8.37$ & $36.0 \pm 7.36$ & \\
\hline Median (IQR) & $30.0(30.0-35.0)$ & $30.0(30.0-40.0)$ & $40.0(30.0-40.0)$ & \\
\hline \multicolumn{4}{|l|}{ After treatment } & \multirow{4}{*}{$\begin{array}{l}\chi_{(\mathrm{KW})}^{2}=0.277 \\
p=0.871\end{array}$} \\
\hline Min; $\max$ & $15.0 ; 60.0$ & $15.0 ; 60.0$ & $15.0 ; 50.0$ & \\
\hline Mean \pm SD & $27.0 \pm 14.55$ & $28.0 \pm 16.5$ & $24.25 \pm 11.39$ & \\
\hline Median (IQR) & $20.0(20.0-32.50)$ & $20.0(15.0-40.0)$ & $20.0(17.5-25.0)$ & \\
\hline \multicolumn{4}{|l|}{ Percentage change } & \multirow{5}{*}{$\begin{array}{l}\chi_{(\mathrm{KW})}^{2}=1.870 \\
p=0.393\end{array}$} \\
\hline Min; $\max$ & $-50.0 ;-66.67$ & $-66.67 ; 66.67$ & $-66.67 ; 66.67$ & \\
\hline Mean \pm SD & $-20.03 \pm 34.63$ & $-19.13 \pm 37.88$ & $-30.82 \pm 32.03$ & \\
\hline Median (IQR) & $-33.33(-36.67$ to -11.11$)$ & $-33.33(-45-16.25)$ & $-37.5(-52.78$ to -20.0$)$ & \\
\hline $\begin{array}{l}\text { Test of significance (within } \\
\text { group) }\end{array}$ & $\begin{array}{l}\mathrm{Z}_{(\mathrm{WSR})}=2.046 \\
p=0.041^{*}\end{array}$ & $\begin{array}{l}\mathrm{Z}_{(\text {WSR }}=1.795 \\
p=0.073\end{array}$ & $\begin{array}{l}\mathrm{Z}_{(\mathrm{WSR})}=3.104 \\
p=0.002 *\end{array}$ & \\
\hline
\end{tabular}

$I Q R$ interquartile range, $K W$ Kruskal-Wallis test, $\max$ maximum, min minimum, $S D$ standard deviation, WSR Wilcoxon signed ranks ${ }^{*} p<0.05$

Table 6 Comparison of systolic and diastolic blood pressure before and after treatment among the three studied groups

\begin{tabular}{|c|c|c|c|}
\hline Blood pressure (mmHg) & $\begin{array}{l}\text { Group } 1 \\
\text { Sildenafil alone }(n=20)\end{array}$ & $\begin{array}{l}\text { Group } 2 \\
\text { Milrinone alone }(n=20)\end{array}$ & $\begin{array}{l}\text { Group } 3 \\
\text { Sildenafil plus } \\
\text { milrinone } \\
(n=20)\end{array}$ \\
\hline \multicolumn{4}{|l|}{ SBP before treatment } \\
\hline Min; $\max$ & $65.0 ; 86.0$ & $68.0 ; 96.0$ & $61.0 ; 98.0$ \\
\hline Mean \pm SD & $75.90 \pm 6.98$ & $80.5 \pm 8.29$ & $81.7 \pm 11.20$ \\
\hline Median (IQR) & $76.5(69.0-81.0)$ & $78.0(74.0-87.5)$ & $81.5(72.5-91.0)$ \\
\hline \multicolumn{4}{|l|}{ SBP after treatment } \\
\hline Min; $\max$ & $52.0 ; 110.0$ & $55.0 ; 114.0$ & $52.0 ; 114.0$ \\
\hline Mean \pm SD & $77.55 \pm 15.12$ & $81.7 \pm 17.43$ & $81.45 \pm 16.39$ \\
\hline Median (IQR) & $77.0(68.0-87.0)$ & $85.0(64.0-93.5)$ & $79.5(72.5-92.0)$ \\
\hline Test of significance & $\begin{array}{l}Z_{\text {(WSR) }}=0.280 \\
p=0.779\end{array}$ & $\begin{array}{l}Z_{(\mathrm{WSR})}=0.262 \\
p=0.794\end{array}$ & $\begin{array}{l}Z_{\text {(WSR) }}=0.242 \\
p=0.809\end{array}$ \\
\hline \multicolumn{4}{|l|}{ DBP before treatment } \\
\hline Min; $\max$ & $34.00 ; 55.00$ & $35.00 ; 61.00$ & $33.00 ; 67.00$ \\
\hline Mean \pm SD & $42.40 \pm 5.59$ & $46.60 \pm 6.83$ & $46.70 \pm 8.52$ \\
\hline Median (IQR) & $40.5(39.0-46.0)$ & $47.0(41.5-49.5)$ & $45.0(40.0-53.50)$ \\
\hline \multicolumn{4}{|l|}{ DBP after treatment } \\
\hline Min; $\max$ & $25.00-58.00$ & $29.0-60.0$ & $30.0-66.0$ \\
\hline Mean \pm SD & $41.3 \pm 8.21$ & $44.90 \pm 10.44$ & $46.65 \pm 9.70$ \\
\hline Median (IQR) & $40.50(35.5-48.00)$ & $49.0(33.0-52.0)$ & $48.0(39.0-52.5)$ \\
\hline Test of significance & $\begin{array}{l}Z_{(\mathrm{WSR})}=0.625 \\
p=0.532\end{array}$ & $\begin{array}{l}Z_{(\mathrm{WSR})}=0.698 \\
p=485\end{array}$ & $\begin{array}{l}Z_{(\mathrm{WSR})}=0.037 \\
p=0.970\end{array}$ \\
\hline
\end{tabular}

$D B P$ diastolic blood pressure, $I Q R$ interquartile range, max maximum, min minimum, $S B P$ systolic blood pressure, $S D$ standard deviation, $W S R$ Wilcoxon signed ranks 
confirm the benefits and evaluate the neurodevelopmental effects of the different treatment modalities in these patients.

\section{Declarations}

Funding This study was funded by the Department of Pediatrics, Faculty of Medicine, Alexandria University, Egypt.

Conflict of interest Mamdouh El-Ghandour, Bahaa Hammad, Mohamed Ghanem, and Manal Antonios have no potential conflicts of interest that might be relevant to the contents of this manuscript.

Ethics approval All procedures performed in this study involving human participants were in accordance with the ethical standards of the national research committee and with the 1964 Helsinki Declaration and its later amendments. The university ethical committee approved the study design.

Informed consent Informed consent was obtained from all patients and caregivers for participation in the study and publication.

Consent to participate All studied cases were asked a written consent after full explanation of the study.

Consent for publication Not applicable.

Availability of data and material All the raw data and master table of the studied cases are available at the corresponding author who is ready to share it with any researcher.

Code availability Not applicable.

Authors' contributions Dr. Mamdouh El-Ghandour invented the idea of this clinical trial and performed the ecchocardiographic assessment of the studied cases blindly. Dr. Bahaa Hammad screened the cases as neonatologist and followed them clinically blindly. Dr. Mohamed Ghanem collected the cases and supervised the double blind technique. Dr. Manal A. M. Antonios supervised data collection, statistical assessment, interpretation and manuscript preparation for publication.

\section{References}

1. Lakshminrusimha S, Steinhorn RH. Pulmonary vascular biology during neonatal transition. Clin Perinatol. 1999;26(3):601-19.

2. Nair J, Lakshminrusimha S. Update on PPHN: mechanisms and treatment. Semin Perinatol. 2014;38(2):78-91.

3. Juliana AE, Abbad FC. Severe persistent pulmonary hypertension of the newborn in a setting where limited resources exclude the use of inhaled nitric oxide: successful treatment with sildenafil. Eur J Pediatr. 2005;164(10):626-9.
4. Pan African Clinical Trial Registry Identifier number PACTR201902691230243. https://pactr.samrc.ac.za/TrialDispl ay.aspx? TrialID=5947. Accessed $17 \mathrm{Feb} 2020$.

5. Heys JJ, Holyoak N, Calleja AM, Belohlavek M, Chaliki HP. Revisiting the simplified Bernoulli equation. Open Biomed Eng J. 2010;4:123-8.

6. Go YY, Dulgheru R, Lancellotti P. The conundrum of tricuspid regurgitation grading. Front Cardiovasc Med. 2018;5:164-7.

7. Kim J, Shin W. How to do random allocation (randomization). Clin Orthop Surg. 2014;6(1):103-9.

8. Faul F, Erdfelder E, Lang AG, Buchner A. G* Power 3: a flexible statistical power analysis program for the social, behavioral, and biomedical sciences. Behav Res Methods. 2007;39(2):175-91.

9. Lobato EB, Beaver T, Muehlschlegel J, Kirby DS, Klodell C, Sidi A. Treatment with phosphodiesterase inhibitors type III and V: milrinone and sildenafil is an effective combination during thromboxane-induced acute pulmonary hypertension. Br J Anaesth. 2006;96(3):317-22.

10. Khorana M, Yookaseam T, Layangool T, Kanjanapattanakul W, Paradeevisut H. Outcome of oral sildenafil therapy on persistent pulmonary hypertension of the newborn at Queen Sirikit National Institute of Child Health. J Med Assoc Thai. 2011;94(Suppl 3):S64-73.

11. Steinhorn RH, Fineman J, Kusic-Pajic A, Cornelisse P, Gehin $\mathrm{M}$, Nowbakht $\mathrm{P}$, et al. Bosentan as adjunctive therapy for persistent pulmonary hypertension of the newborn: results of the randomized multicenter placebo-controlled exploratory trial. J Pediatr. 2016;177(90-6):e3.

12. Prithviraj D, Reddy B, Abhijit D, Reddy R. Oral sildenafil in persistent pulmonary hypertension of the newborn in invasive and non-invasive ventilated babies-its effect on oxygenation indices. Int J Sci Stud. 2016;4(2):203-9.

13. Kato R, Sato J, Nishino T. Milrinone decreases both pulmonary arterial and venous resistances in the hypoxic dog. Br J Anaesth. 1998;81(6):920-4.

14. Chang AC, Atz AM, Wernovsky G, Burke RP, Wessel DL. Milrinone: systemic and pulmonary hemodynamic effects in neonates after cardiac surgery. Crit Care Med. 1995;23(11):1907-14.

15. Chen EP, Bittner HB, Davis RD, Van Trigt P. Hemodynamic and inotropic effects of milrinone after heart transplantation in the setting of recipient pulmonary hypertension. J Heart Lung Transplant. 1998;17(7):669-78.

16. Baquero H, Soliz A, Neira F, Venegas ME, Sola A. Oral sildenafil in infants with persistent pulmonary hypertension of the newborn: a pilot randomized blinded study. Pediatrics. 2006;117(4):1077-83.

17. Vargas-Origel A, Gomez-Rodriguez G, Aldana-Valenzuela C, Vela-Huerta MM, Alarcon-Santos SB, Amador-Licona N. The use of sildenafil in persistent pulmonary hypertension of the newborn. Am J Perinatol. 2010;27(3):225-30. 